\title{
The Final Ecosystem Goods \& Services (FEGS) Approach: A Beneficiary-Centric Method to Support Ecosystem-Based Management
}

\author{
Theodore H. DeWitt, Walter J. Berry, Timothy J. Canfield, \\ Richard S. Fulford, Matthew C. Harwell, Joel C. Hoffman, \\ John M. Johnston, Tammy A. Newcomer-Johnson, \\ Paul L. Ringold, Marc J. Russell, Leah A. Sharpe, and \\ Susan H. Yee
}

T. H. DeWitt $(\bowtie)$

US Environmental Protection Agency, Pacific Ecological Systems Division, Newport, OR, USA

e-mail: dewitt.ted@epa.gov

W. J. Berry

US Environmental Protection Agency, Atlantic Coastal Environmental Sciences Division, Narragansett, RI, USA

T. J. Canfield

US Environmental Protection Agency, Groundwater Characterization and Remediation Division, Ada, OK, USA

R. S. Fulford · M. C. Harwell · L. A. Sharpe · S. H. Yee

US Environmental Protection Agency, Gulf Ecosystem Measurement and Modeling Division, Gulf Breeze, FL, USA

J. C. Hoffman

US Environmental Protection Agency, Great Lakes Toxicology and Ecology Division, Duluth, MN, USA

J. M. Johnston

US Environmental Protection Agency Office Research and Development, Environmental Processes Division, Athens, GA, USA

T. A. Newcomer-Johnson

US Environmental Protection Agency, Watershed and Ecosystem Characterization Division, Cincinnati, OH, USA

P. L. Ringold

US Environmental Protection Agency, Pacific Ecological Systems Division, Corvallis, OR, USA

M. J. Russell

US Environmental Protection Agency, Center for Computational Toxicology and Exposure, Gulf Breeze, FL, USA 


\begin{abstract}
Ecosystem-Based Management (EBM) and other social-ecological environmental management frameworks recognize that most environmental problems are ultimately social problems, requiring the reconciliation of human needs with the limits of ecosystem productivity and resilience. Using a social-ecological perspective in management practice can be greatly facilitated by identifying the attributes of ecosystems that are directly used, enjoyed, or appreciated by people connected to the environmental issue at hand. These are the final ecosystem goods and services (FEGS), which are specific to ecosystem types and how people use or appreciate ecological attributes of those ecosystems. This article: (1) reviews the conceptual basis of a FEGS approach for linking people's well-being to ecosystems; (2) describes how FEGS are identified, organized, and measured using classification systems, and metrics and indicators; and (3) presents examples of how the FEGS approach can be integrated into EBM and other decision-making frameworks.
\end{abstract}

\title{
Lessons Learned
}

- FEGS are the subset of ecosystem services that are directly used, enjoyed, or appreciated by people. Individual FEGS are identified as the biophysical attributes found within a given ecosystem that are used, enjoyed, or appreciated for a specific purpose.

- FEGS facilitate identifying, quantifying, and assigning value to biophysical attributes of ecosystems that are of greatest relevance to people who care about or depend on those ecosystems.

- FEGS are useful for communicating with stakeholders and policy-makers about how people obtain specific benefits from specific biophysical attributes of an ecosystem.

- Tools have been developed to identify FEGS within all types of ecosystems found on earth, for working with stakeholders to prioritize which FEGS are of greatest concern within a given decision context, and to identify mathematical models useful for estimating FEGS production.

\section{Needs to Advance EBM}

- Greater awareness within the EBM community of practice, including developing case-study applications, of the usefulness of FEGS and the availability of tools useful for identifying, prioritizing, and quantifying them.

- A standardized list of metrics or indicators for each FEGS, based on the attributes of ecosystem types that each beneficiary class uses, enjoys, or appreciates. Sitespecific metrics or indicators could then be developed from those generic attributes.

- Integration of the FEGS tools (e.g., NESCS Plus, FEGS Scoping Tool, Rapid Benefits Indicators, EcoService Models Library) to facilitate identification of priority FEGS, relevant metrics and indicators for FEGS endpoints and benefits, and models for estimating responses of those FEGS to environmental change or stressors. 


\section{Introduction}

Humankind depends wholly on nature for its well-being. An array of ecosystem goods and services, often available at no apparent cost, sustains our health, economy, and society. Those aspects of nature that people benefit from include productive soil for farmers, clean and safe water for swimmers, and inspirational landscapes for artists. The key feature of the examples in this list are that they link a good or service that is provided by nature to a specific type of beneficiary, or user group. Those ecosystem products and processes that are directly used, enjoyed, or appreciated by people are identified as Final Ecosystem Goods and Services (FEGS) (Boyd and Banzhaf 2007; Boyd et al. 2016). Those FEGS are a subset of all ecosystem goods and services (e.g., MEA 2005; Haines-Young and Potschin 2018) distinguished as the final "endpoints" in nature's production networks that people directly use (Fig. 1). The production of FEGS is dependent on "supporting" and "regulating" ecological functions; these intermediate processes (Potschin-Young et al. 2017) are critically important to human well-being, for without them, FEGS would not exist. This is the essence of the FEGS approach: making explicit the biophysical attributes of ecosystems from which specific beneficiaries obtain a specific benefit. Beneficiaries are "the interests of an individual (i.e., person, group, and/or firm) that drive active or passive consumption and/or appreciation of ecosystem services resulting in an impact (positive or negative) on their welfare" (Nahlik et al. 2012). For example, beneficiaries are recreational anglers who fish for wild fish for food or pleasure, industrial processors who use water for cooling or product manufacturing, or artists who use attributes of nature for inspiration to produce art (Landers and Nahlik 2013). Beginning from this beneficiary perspective, we identify and quantify the biophysical attributes of ecosystems that people use or appreciate in order to achieve a wide

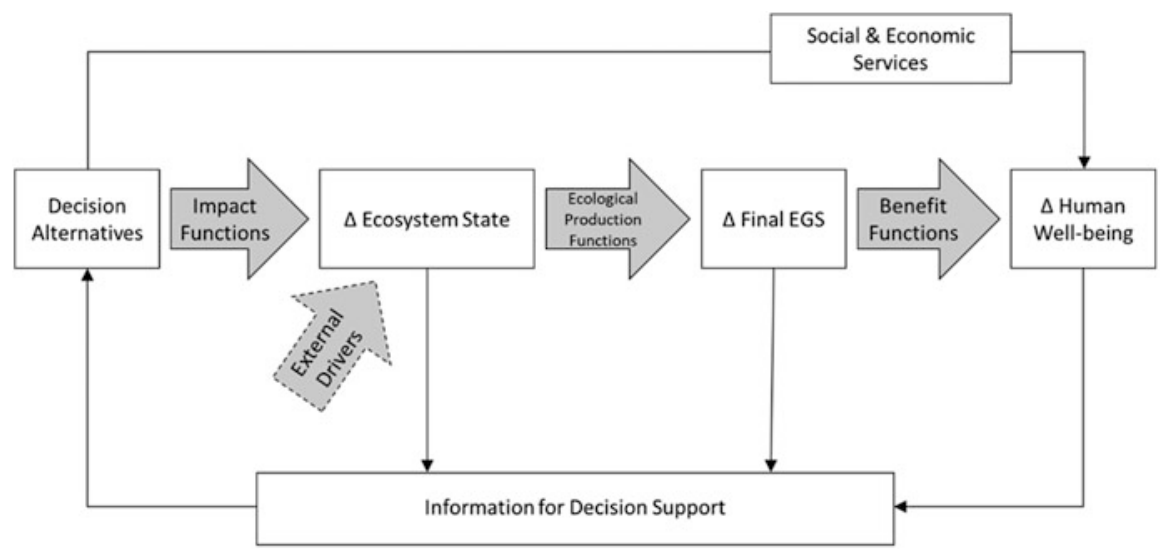

Fig. 1 Conceptual model for how changes to the state of an ecosystem (e.g., its biophysical attributes) and consequent changes in the production of final ecosystem goods and services (FEGS) influence environmental decision-making via impacts to human well-being. For more on this conceptual model, see Harwell and Molleda (2018) 
range of benefits. In this chapter, we describe steps being taken to incorporate FEGS into decision-making and policies using: a classification system that identifies the beneficiaries and ecosystem attributes for each FEGS; methods to measure or estimate (through modeling) FEGS stocks, production and value; and decisionsupport tools to facilitate integrating FEGS into decision making.

Identifying, quantifying, and forecasting the stocks, production, and value of FEGS are important for demonstrating the relevance of natural systems to the public and policy makers, and they are fundamental to understanding the capacity of an area, or an ecosystem, to produce natural goods and services used by or useful to people. Characterization of FEGS is thus a valuable communication tool that provides support and added justification for ecosystem protection in decision making, including tradeoff analyses. At the same time, the identification of FEGS facilitates investigation into the social-ecological interactions between human actions, ecosystem condition, human well-being, a renewed reason to better understand how ecosystems function, and a basis for prioritizing which ecological attributes and processes should be incorporated into environmental management and policy.

The FEGS approach requires a subtle but important shift in perspectives in ecosystem services science, from identifying ecological goods and services that are important to human well-being (MEA 2005), to identifying what attributes of ecosystems people use, enjoy, or appreciate to fulfill a specific interest, and recognizing that the attributes that people use in pursuit of those interests differ across ecosystem types (Ringold et al. 2013). In other words, the FEGS approach is predicated on the fact that people use or depend on ecosystems in different ways, contingent on what they are doing or needing at a given moment and where those people are located (e.g., within what type of ecosystem). An important aspect of this beneficiary perspective is the inclusion of a wide range of human interests, including those related to culture and spirituality, as well as to health, economic, and overall well-being. By recognizing the importance of the human relationship to ecosystems, the beneficiary perspective addresses the concern that traditional resource management emphasizes goods and services (i.e., using metrics such as fisheries yield or recreational days) without explicitly considering the social context of a problem and the depth of the relationship between beneficiaries and the environment (Grumbine 1994).

In this chapter, we: (1) review the concept of the FEGS approach to human-nature interactions; (2) describe how FEGS are identified, organized, and measured using classification systems, and metrics and indicators; and (3) present examples of how the FEGS approach can be integrated into decision making, specifically to support Ecosystem-Based Management (EBM).

\section{The FEGS Approach}

The FEGS approach (Fig. 2) is motivated by the idea that identifying the biophysical attributes of ecosystems that are relevant to people will facilitate holistic benefit and economic assessment (Boyd et al. 2015). A key challenge for scientists is to identify 
"[biophysical] components... of nature.... directly enjoyed, consumed, or used"

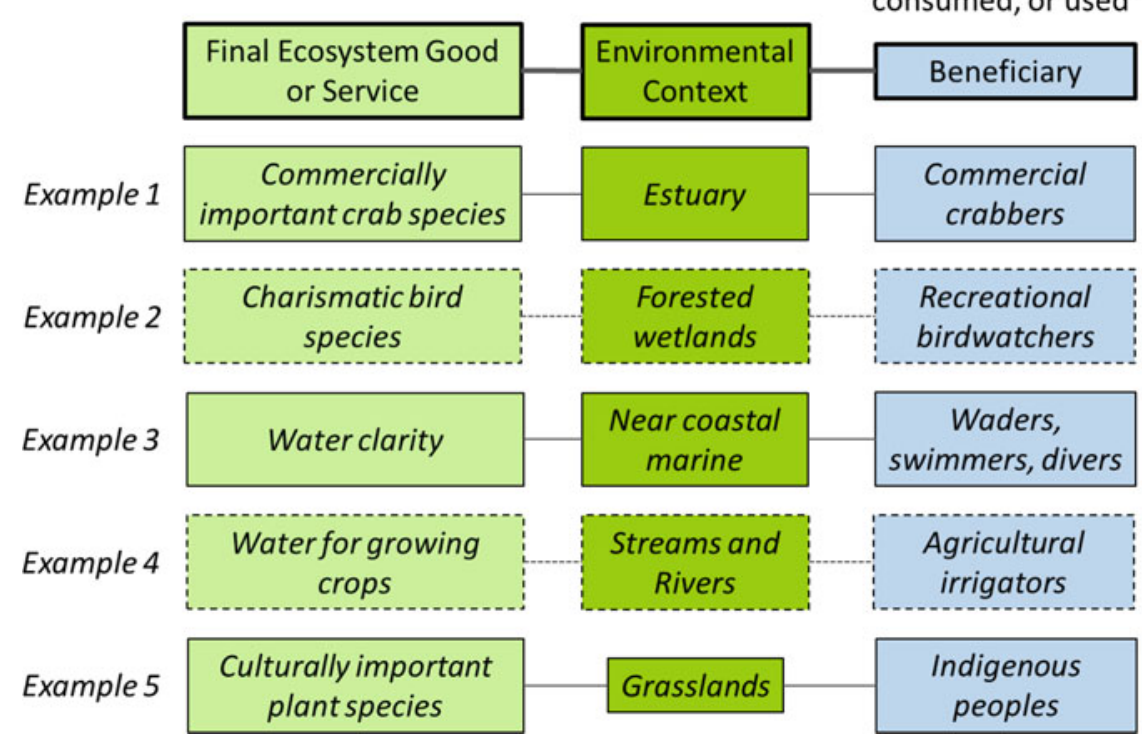

Fig. 2 Illustration and examples of the three elements needed to define FEGS. Note that many, if not most, beneficiaries depend directly on multiple biophysical attributes of multiple ecosystems rather than the single ones shown here

and measure biophysical attributes that are most relevant to human well-being (Boyd and Banzhaf 2007; Landers and Nahlik 2013; Boyd et al. 2015). In the FEGS approach, specification of the beneficiary must come before identification of which biophysical attributes should be measured. The benefits that groups of people obtains from nature are determined by how they use, enjoy, or otherwise depend on nature. To facilitate the identification of FEGS endpoints, people are grouped into beneficiary classes that describe their interests which drive the consumption, use, or appreciation of ecosystem goods or services (Landers and Nahlik 2013). Then, the ways that a given beneficiary class interacts with a given ecosystem to obtain those good and services determines the biophysical component of a specific FEGS. Note that FEGS do not include the ecological components or processes that are necessary to produce it, which are intermediate processes (Haines-Young and Potschin 2018). Additionally, it is important to acknowledge that FEGS for one beneficiary (e.g., water temperature for an aquaculturalist) may be an intermediate process for another (e.g., a recreational angler).

The FEGS approach can bring clarity to environmental management by translating intermediate ecological processes into FEGS by asking the following questions (Table 1):

- "Who are the beneficiaries?"

- "How and where (i.e., in what ecosystem type) do they use, enjoy or appreciate nature?" 
Table 1 Examples of how starting with the beneficiaries can help bridge intermediate ecosystem processes with their beneficiaries (bold), the FEGS attributes they use or enjoy (italics), and the relevant environmental context (underline)

\begin{tabular}{|c|c|c|}
\hline $\begin{array}{l}\text { Intermediate } \\
\text { processes }\end{array}$ & Beneficiary-oriented questions & FEGS approach \\
\hline $\begin{array}{l}\text { Habitat for } \\
\text { fauna }\end{array}$ & $\begin{array}{l}\text { Who are the beneficiaries and what do } \\
\text { they use, appreciate, or enjoy about } \\
\text { habitat? }\end{array}$ & $\begin{array}{l}\text { - Recreational hunters hunt game } \\
\text { animals when visiting forested areas in } \\
\text { the region } \\
\text { - Recreational birders want to see } \\
\text { a specific species of charismatic bird } \\
\text { and are thus drawn to wetlands in the } \\
\text { region }\end{array}$ \\
\hline $\begin{array}{l}\text { Water qual- } \\
\text { ity regulation }\end{array}$ & $\begin{array}{l}\text { Who are the beneficiaries and what do } \\
\text { they use, appreciate, or enjoy about } \\
\text { water quality? }\end{array}$ & $\begin{array}{l}\text { - Residents, dependent on drink- } \\
\text { ing water aquifers, are concerned } \\
\text { about water salinity in groundwater } \\
\text { - Snorkelers are concerned about } \\
\text { water turbidity in popular coastal waters } \\
\text { - Commercial fishermen are } \\
\text { concerned about contaminants in edible } \\
\text { fish tissue in the lakes they frequent }\end{array}$ \\
\hline $\begin{array}{l}\text { Water quan- } \\
\text { tity } \\
\text { regulation }\end{array}$ & $\begin{array}{l}\text { Who are the beneficiaries and what do } \\
\text { they use, appreciate, or enjoy about } \\
\text { water quantity? }\end{array}$ & $\begin{array}{l}\text { - Municipal drinking-water plant } \\
\text { operators care about the reliable avail- } \\
\text { ability of fresh water from streams } \\
\text { - Coastal home owners directly } \\
\text { understand the value of shoreline pro- } \\
\text { tection through dunes and vegetation in } \\
\text { reducing the probability of property } \\
\text { damage due to erosion by waves }\end{array}$ \\
\hline
\end{tabular}

- "What ecological end-products (EEPs) do they use, enjoy or appreciate"

- "Where is the EEP located (i.e., ecosystem type) that is used, enjoyed, or appreciated?"

In a given lake, for example, while recreational boaters might be concerned about water clarity, odor, or having sufficient water depth in which to operate a boat, an industrial processor will be primarily concerned with water corrosiveness, presence of biofouling organisms, and the reliability of water quantity. Taking a FEGS approach helps ensure that the full range of benefits is considered by identifying meaningful biophysical indicators or metrics to be monitored, valued, and reported. A FEGS approach also facilitates communication about what matters to people by ensuring that key issues or stakeholders are not overlooked, and by allowing management decisions to include things people care about and understand (Yee et al. 2017). 


\subsection{FEGS Classification System}

Several frameworks have been proposed for classifying ecosystem services (e.g., MEA 2005; Haines-Young and Potschin 2018; Landers and Nahlik 2013; US EPA 2015). Finisdore et al. (2018) describes a suite of classification systems and outlines the range of benefits of using classification systems. The goals of these classification systems are to develop a common, shared language in an interdisciplinary field and provide a consistent framework for identifying, organizing, and accounting for ecosystem services. Two classification systems for FEGS have been developed by the US EPA to identify the types of uses, needs, or desires that a beneficiary seeks to obtain from a given ecosystem type from specific biophysical attributes present there. A FEGS approach facilitates the creation of information useful for valuation and helps to minimize double counting and valuation problems regarding intermediate processes that are not clearly distinguished from FEGS (Ojea et al. 2012; Nahlik et al. 2012). The FEGS Classification System (FEGS-CS) was developed to help "determine those specific ecosystem attribute(s) associated with the specific FEGS that the beneficiary values" such that "these can directly lead to identifying appropriate metrics and indicators for FEGS" (Landers and Nahlik 2013). The FEGS-CS was created primarily to aid in organizing ecological metrics and indicators that would provide meaningful input to environmental benefit assessment and policy decisions. The National Ecosystem Services Classification System (NESCS) was developed by environmental economists (US EPA 2015). The NESCS comprehensively and uniquely identifies distinct categories of FEGS to support analysis of how changes in ecosystems affect human well-being by applying, adapting, and combining the principles underlying existing economic accounting systems for market goods and services, primarily for use in environmental accounting (Russell et al. 2020). The NESCS defines the ecological attributes of an environment that flow as inputs to human uses (both market and non-market) to both emphasize human reliance on these flows and to illustrate how changes in policy could affect those flows and the well-being they provide to human users of those environments. The NESCS also links to standard accounting systems (such as the North American Industry Classification System, NAICS; https://www.census.gov/eos/www/naics/) and more directly to existing economic valuation practices than does the FEGS-CS (US EPA 2015). The US EPA is nearing completion of a merged classification system (NESCS Plus) to leverage the best of both systems. The NESCS Plus will reduce confusion caused by parallel classification systems and be consistent with prior systems so that it remains relevant for audiences of FEGS-CS and NESCS.

\subsection{FEGS Metrics and Indicators}

The metrics and indicators associated with FEGS are important for incorporating definable benefits that people receive from nature into elements of decision-making 


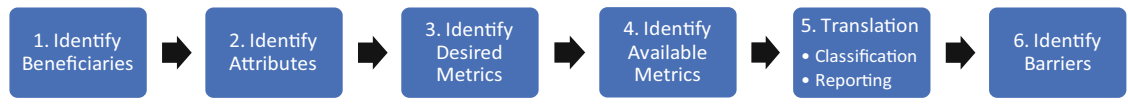

Fig. 3 Developing FEGS metrics and indicators for a given environment type is a 6-step process starting with beneficiaries and the attributes of nature that they value

processes (e.g., issue identification, options analysis, communication), as well as overall decision-making processes such as EBM and Structured Decision-Making (SDM).). In particular, the ecosystem-based framework underpinning FEGS-based classification systems allows analysts to view comprehensively the biophysical attributes (e.g., wild food, drinkable water, specific organisms) and resulting human benefits (e.g., nutrition, recreation, improved health, spiritual enrichment) provided by an ecosystem (Landers and Nahlik 2013). Further, FEGS-based classification systems identify classes of beneficiaries or users (e.g., commercial harvesters, recreational anglers, boaters) that potentially benefit from FEGS when they interact with nature. A simultaneous comparison of the different FEGS that might benefit each beneficiary or user group affected by a management option provides a complete summary and representation of the ways in which people may be impacted by management decisions. Synergies and trade-offs among groups of beneficiaries are expected. That is, an increase in a good or service of value to one group could either support a related increase to another beneficiary group or result in a reduction of a good or service to another group. For example, an increase in clean water for swimmers might also benefit recreational anglers, but an increase in complex reef structure that provides superior habitat to produce fish may be desirable to scuba divers (i.e., tourism), but undesirable for commercial and recreational fishing (e.g., due to gear entanglement).

Developing metrics and indicators of FEGS for a given ecosystem type begins with identifying which beneficiary groups directly interact with that ecosystem, then considers what specific components of nature are directly used, enjoyed, or appreciated by each beneficiary group, and moves to considering how those components could be measured directly (Fig. 3; Ringold et al. 2013). Typically, each beneficiary group will directly use, appreciate, or enjoy multiple biophysical attributes within a given ecosystem, with each attribute represented by one or more metrics. Those attributes may be identified by considering what individual people directly perceive or interact with from the environment. For example, an individual partaking in recreational angling within an estuary may care directly about the taxa and size of the fish she might catch, whether the fish she catches are safe to eat, whether the conditions at the site are safe, and/or whether the aesthetics of the site are appealing (Table 2). That is because an individual can use different attributes of an ecosystem depending which one of many "roles" she is playing (e.g., catch and release fisherman, subsistence fisherman, experiencer of natural place, etc.) while doing an activity as complex as recreational angling. Direct measurement of some attributes may be difficult or expensive (e.g., angler success in fishing), necessitating the use of surrogate metrics that approximate the suite of valued attributes (e.g., percent 


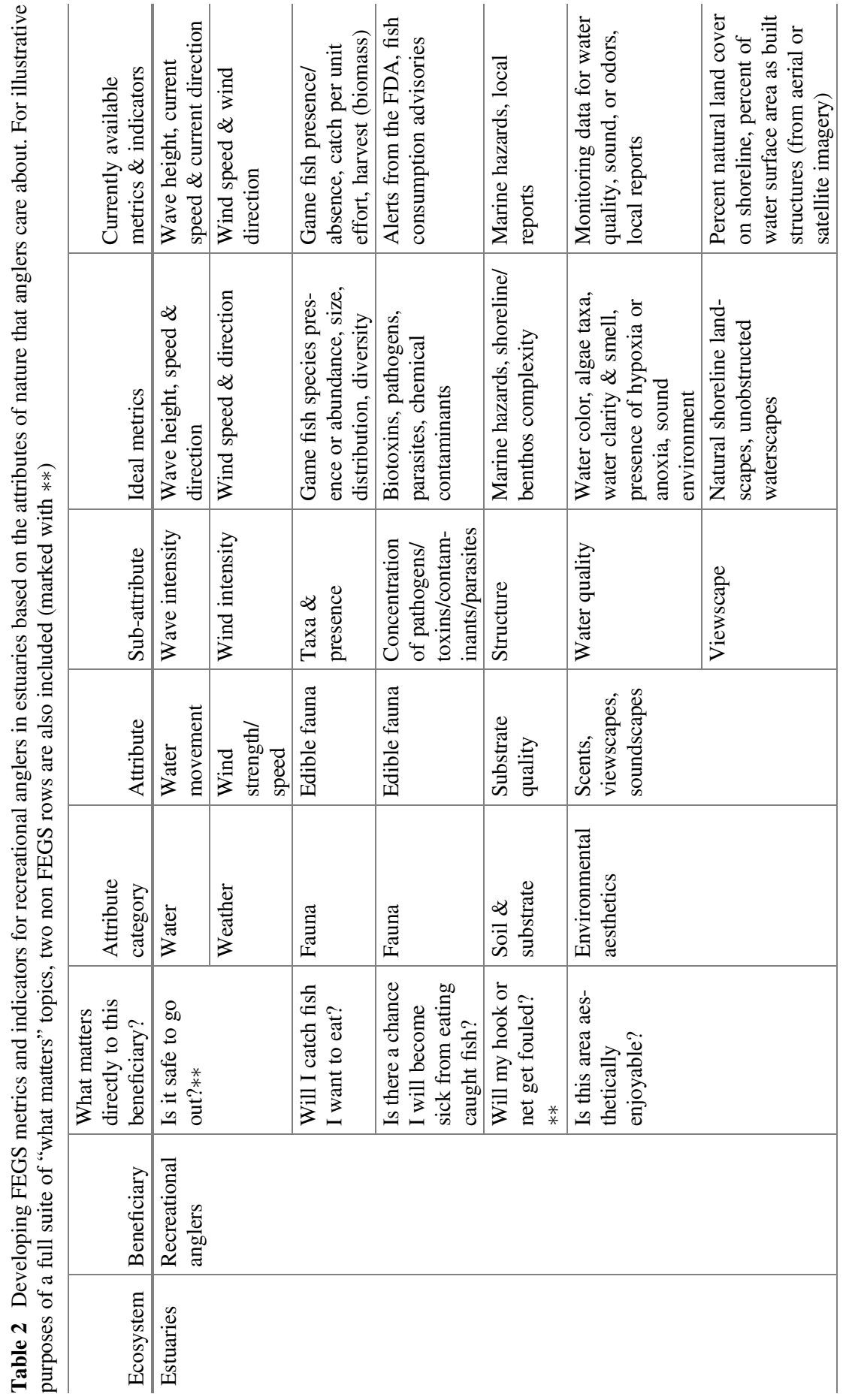


of natural land cover along shorelines) while acknowledging the limitations of using surrogates. An important distinction here is ideal metrics versus available, or surrogate, metrics. While we need to specify the ideal metrics, we must then quantify them within budget, time, and available data constraints.

Identifying those metrics that closely represent how beneficiaries use attributes of nature facilitates the translation of data obtained with those metrics into information that analysts, stakeholders, and the public can use in their decision processes (Wainger and Mazzotta 2011). Balanced against that ideal is the pragmatic desire to use both existing metrics (i.e., to minimize methodology development) and existing data. Wainger and Mazzotta (2011) suggest that ideal FEGS metrics are:

- Easily understood by non-experts

- As close to the FEGS as possible (e.g., the taxa, size, condition, and abundance of game fish, as opposed to the total number of all fish at a location)

- Readily available (e.g., existing methodology and data sets)

- Available for large areas

- Available at a user-appropriate scale as defined by the management or user question(s) and by the beneficiary perceptions (e.g., a recreational angler might want data on the scale of an individual fishing spot, while a fisheries regulator might need information at a statewide or regional scale).

The number of FEGS metrics that need to be measured depends on the problem requirements. The list of all potential FEGS metrics for any ecosystem type can be quite extensive if the interests of all potential beneficiaries are considered. From an operationalizing perspective, however, analysts, stakeholders, or managers may determine that the classification of beneficiaries or ecosystem types (e.g., for each of the FEGS classification systems) may be too general for the problem at hand. That could drive the need for a narrower specification of beneficiaries, ecosystem sub-types, or ecosystem attributes, and consequently, a refined set of relevant metrics. The FEGS Scoping Tool (Sharpe et al. 2020) was developed to help stakeholders or managers collaboratively and transparently identify common interests and prioritize the attributes of nature that are most valued across beneficiary groups. Analysts can draw from existing sets of FEGS metrics or build from those to identify metrics relevant to quantifying and sustaining the stakeholders' most valued benefits of nature.

\section{Operationalizing the FEGS Approach}

\subsection{Role of FEGS in Ecosystem-Based Management (EBM)}

The FEGS approach can provide several important tools for EBM. First, the categorization of beneficiaries of FEGS helps to specify who the stakeholders are whose wants, needs, desires, and perceptions need to be addressed (Ringold et al. 2013; Landers et al. 2016). Those beneficiaries may live within or adjacent to an ecosystem 
(e.g., coastal communities) or distantly, and may come from diverse socio-economic groups. The potential for heterogeneity in their values needs to be considered when assigning weights to biophysical outcomes. Second, a FEGS-based classification system informs the selection of metrics or indicators useful for identifying, communicating, and quantifying the ecological attributes for application in assessing or monitoring FEGS, their production, or their use or appreciation by people. Third, identification of beneficiaries and associated FEGS informs the selection and development of models to forecast production of FEGS (i.e., ecological production functions; Wainger and Mazzotta 2011; Bruins et al. 2017), the delivery of benefits to people (i.e., benefit functions; Wainger and Mazzotta 2011; Villa et al. 2014; Bousquin and Mazzotta 2020), and integrated ecological-social well-being frameworks (Schlueter et al. 2012).

Identification of the beneficiaries of FEGS within an area of interest, and the ecological attributes that the beneficiaries use, helps decision makers understand the types and magnitudes of the tradeoffs involved in policy options, how beneficiaries will be affected by changing conditions within the ecosystem, the biophysical features of the ecosystem that are important to those beneficiaries, where and how beneficiaries experience those biophysical features, and where and how those biophysical features are produced. For example, the US EPA's Remediation-to-Restoration-to-Revitalization (R2R2R) program for contaminated-site clean-up actions around the U.S. Great Lakes inherently uses a beneficiary-centric, FEGS approach by working towards each community's vision for their desired human-nature outcomes (i.e., revitalization), and incorporates those outcomes into the goals of each phase of the clean-up and restoration (Williams and Hoffman 2020). In combination, this information can inform prioritization and local management relative to ecosystem goals and help to align decision-making with local values.

\subsection{Integrating FEGS Into a Structured Decision Making (SDM) Framework, and Relevance to EBM}

Structured Decision Making (SDM) provides an organizing framework to formally integrate FEGS, or any other approaches and tools into EBM (Gregory et al. 2012; also see Sharpe et al. 2020). The use of SDM places a strong emphasis on problem structuring by clarifying the problem, identifying objectives (i.e., separating those objectives to accomplish at the end from those objectives that are important ways to reach end objectives), and developing meaningful measures (Marcot et al. 2012; Maseyk et al. 2017). The use of SDM is an alternative to technical assessments or cost-benefit analysis, which may be done along with SDM, but are not required. Without clarifying "what really matters" upfront, resources can be wasted collecting the wrong information for the wrong problem, leading to irrelevant or misleading assessments (Carriger et al. 2013). A focus on what stakeholders' value, in contrast, can lead to more creative and effective outcomes. The FEGS approach can facilitate 
management decisions and actions that have a higher likelihood of acceptance across a variety of stakeholders because they are based on the stakeholders' priorities.

An SDM process includes a series of steps similar to other decision processes (Table 3) and can be used to identify where FEGS concepts can be integrated into an EBM decision process even while using other decision frameworks, such as AQUACROSS (Piet et al. 2017, 2020), an EBM policymaking framework (Cormier et al. 2017), or integrated ecosystem assessment (Foley et al. 2013). Each decision framework has a unique set of steps, but FEGS concepts can still be integrated at many places within each process (Table 3).

The FEGS approach advances the ability to identify, articulate, measure, and assess the potential role of relevant ecosystem goods and services in a given decision context. Using FEGS metrics or indicators, for example, may provide more relevant assessment endpoints for EBM and enable communication of benefits to humans better than endpoints that are difficult to link to human use (e.g., total primary production, $\mathrm{pH}$, species diversity, etc.). The use of FEGS metrics should also be useful for regulatory purposes, such as risk assessment endpoints (Munns et al. 2017). Additionally, having a consistent approach for defining EBM terminology (Arkema et al. 2006) and clear articulation of EBM principles (Delaclamara et al. 2020) will help practitioners identify how to incorporate ecosystem services and decision strategies for a given EBM context. Further, the FEGS approach and tools presented here help EBM practitioners identify users or beneficiaries who will be affected by environmental changes at a site due to changes in the specific ecological attributes that those groups derive benefit from, for a given decision context (Fig. 4).

Within a larger SDM framework, the FEGS approach can also assist EBM practitioners identify and prioritize stakeholders to bring into the decision process (i.e., using the FEGS Scoping tool; Sharpe et al. 2020). Because FEGS are the link between biophysical condition and socio-economic benefits to people, this approach is compatible with socio-ecological systems frameworks (Elliott and O'Higgins 2020; Piet et al. 2020). By connecting ecosystem services directly to human health and well-being endpoints within a structured framework, the FEGS approach lends itself to systems analysis (including linkage frameworks, network analysis, and Health Impact Assessments (HIA)); Robinson and Culhane 2020; Williams and Hoffman 2020) for identifying and evaluating key stressors in the system or vulnerabilities to ecosystem-services supply that may need to be prioritized for management. Additionally, the FEGS approach helps advance efforts to develop classification systems useful for a range of EBM practitioners (Culhane et al. 2020). These classification systems can be leveraged to identify ecosystem-services focused metrics and indicators that can inform the evaluation of management alternatives.

Decision analysis tools, such as means-ends networks, direct ranking, swing weighting, or consequence tables (Gregory et al. 2012) can be used to identify management actions that might improve ecosystem services production or where ecosystem services may be a means to achieving other social or economic objectives. Because FEGS are closely linked to human beneficiaries, the FEGS approach fosters the identification and application of relevant tools across the SDM cycle (Fig. 4; Yee et al. 2017), such as for prioritizing and measuring economic benefits of ecosystem 


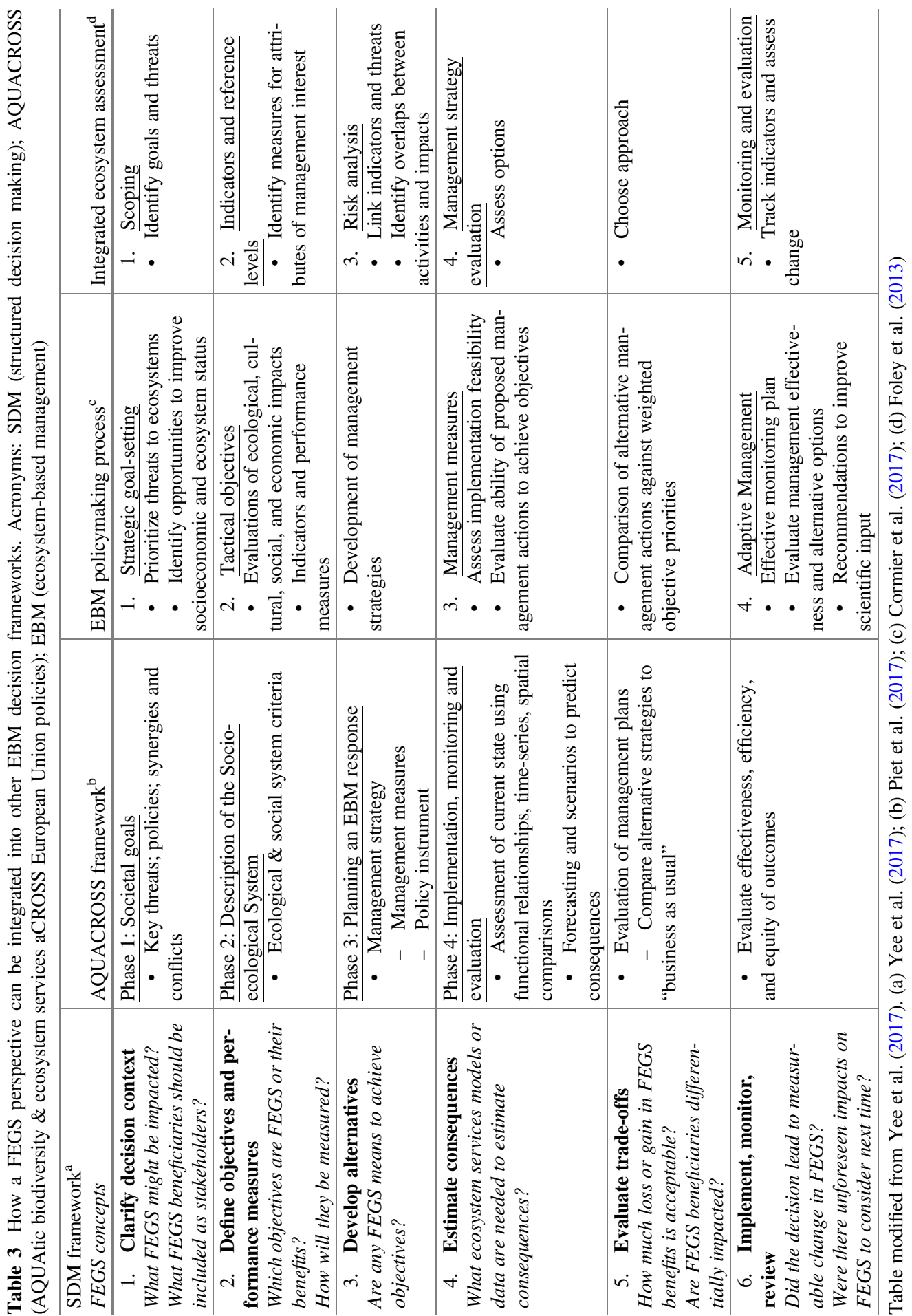




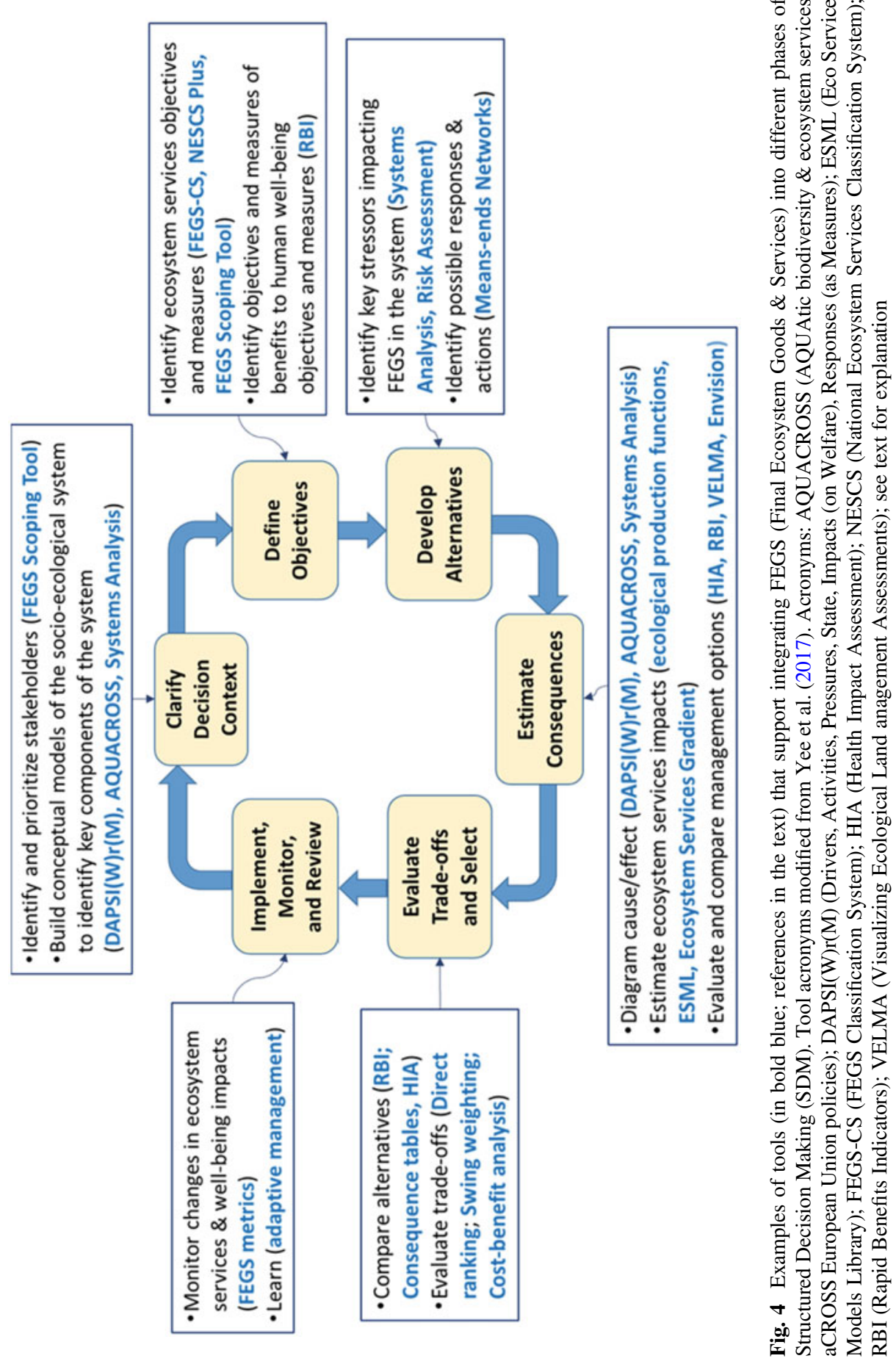


services using the related Rapid Benefits Indicators (RBI) approach (Bousquin and Mazzotta 2020).

Ecological production functions (e.g., models useful for estimating ecosystem services) can be utilized in an EBM context to quantitatively predict changes in ecosystem services in response to changes in a system, management alternatives for a decision context (Fulford et al. 2020; Lewis et al. 2020). In some cases, expert knowledge and synthesis of available data may be sufficient, or used in combination with quantitative modelling, to communicate how usage of natural resources changes in response to changes in ecological conditions (e.g., ecosystem services gradients; Yee et al. 2020). Different models may be integrated and applied within decision support systems (e.g., Envision, VELMA; McKane et al. 2020) to evaluate and compare the impacts of alternative management options on ecosystem services or other relevant objectives.

\section{Summary}

This chapter outlined the suite of concepts, methods, and tools that comprise the FEGS approach and demonstrates steps taken to incorporate the approach into decision-making for EBM. The FEGS approach focuses on advancing both the field of ecosystem services science and the utilization of decision-making frameworks to the field of EBM (Delacámara et al. 2020). One important application of the FEGS approach is to aid in guiding the development of ecological endpoints and metrics useful for assessment of stocks or site/system conditions for EBM. The foundational research across elements of the FEGS approach has been made operational across a suite of case studies and decision contexts, including examining alternatives in coastal forest management in the U.S. Pacific Northwest (McKane et al. 2020), cleanup of contaminated sites in the Great Lakes (Williams and Hoffman 2020), resiliency planning following natural disasters (Myer and Johnston 2020), restoring large ecosystems such as the Everglades (Gibble et al. 2020), and examining ecosystem management practices among different future climate scenarios in the Lower Mekong Basin (Johnston et al. 2020).

The FEGS approach can also be useful to EBM practitioners through the development of strategic communication messages (Harwell et al. 2020) for stakeholders and the public regarding the benefits associated with pending or implemented decisions. In particular, the FEGS approach aids in communicating which people within a system (i.e., beneficiary groups) will be affected by changes to the condition of the environment owing to how those changes will affect the benefits (i.e., health, economic, or social) people obtain from nature (Fig. 1). For example, recent work has advanced the field of biological condition gradients used to characterize and communicate the status of an ecosystem in relation to thresholds of meaningful change and potential management actions to incorporate ecosystem services (Yee et al. 2020). Overall, the approach of starting with human beneficiaries and asking what they use, appreciate, or enjoy about ecosystems holds promise for advancing 
ecosystem goods and services science to support environmental decision making, particularly ecosystem-based management.

Disclaimer This chapter has been subjected to Agency review and has been approved for publication. The views expressed in this paper are those of the author(s) and do not necessarily reflect the views or policies of the U.S. Environmental Protection Agency.

\section{References}

Arkema, K. K., Abramson, S. C., \& Dewsbury, B. M. (2006). Marine ecosystem-based management: From characterization to implementation. Frontiers in Ecology and the Environment, 4 (10), 525-532.

Bousquin, J., \& Mazzotta, M. (2020). Rapid benefit indicator tools. In T. O’Higgins, M. Lago, \& T. H. DeWitt (Eds.), Ecosystem-based management, ecosystem services and aquatic biodiversity: Theory, tools and applications (pp. 309-332). Amsterdam: Springer.

Boyd, J., \& Banzhaf, S. (2007). What are ecosystem services? The need for standardized environmental accounting units. Ecological Economics, 63, 616-626.

Boyd, J. W., Ringold, P. L., Krupnick, A. J., Johnston, R. J., Weber, M., \& Hall, K. (2015). Ecosystem services indicators: Improving the linkage between biophysical and economic analyses. RFF DP 15-40, Resources for the Future, Washington, DC.

Boyd, J., Ringold, P., Krupnick, A., Johnston, R. J., Weber, M. A., \& Hall, K. (2016). Ecosystem services indicators: Improving the linkage between biophysical and economic analyses. International Review of Environmental and Resource Economics, 8(3-4), 359-443. https://doi.org/ 10.1561/101.00000073.

Bruins, R. J. F., Canfield, T. J., Duke, C., Kapustka, L., Nahlik, A. M., \& Schäfer, R. B. (2017). Using ecological production functions to link ecological processes to ecosystem services. Integrated Environmental Assessment, 13(1), 52-61.

Carriger, J. F., Fisher, W. S., Stockton, T. B., \& Sturm, P. E. (2013). Advancing the Guánica Bay (Puerto Rico) watershed management plan. Coastal Management, 41(1), 19-38.

Cormier, R., Kelble, C. R., Anderson, M. R., Allen, J. I., Grehan, A., \& Gregersen, O. (2017). Moving from ecosystem-based policy objectives to operational implementation of ecosystembased management measures. ICES Journal of Marine Science, 74, 406-413.

Culhane, F. E., Robinson, L. A., \& Lillebø, A. I. (2020). Approaches for estimating the supply of ecosystem services: Concepts for ecosystem-based management in coastal and marine environments. In T. O'Higgins, M. Lago, \& T. H. DeWitt (Eds.), Ecosystem-based management, ecosystem services and aquatic biodiversity: Theory, tools and applications (pp. 105-126). Amsterdam: Springer.

Delacámara, G., O’Higgins, T., Lago, M., \& Langhans, S. (2020). Ecosystem-based management: moving from concept to practice. In T. O'Higgins, M. Lago, \& T. H. DeWitt (Eds.), Ecosystembased management, ecosystem services and aquatic biodiversity: Theory, tools and applications (pp. 39-60). Amsterdam: Springer.

Elliott, M., \& O'Higgins, T. G. (2020). From the DPSIR, the D(A)PSI(W)R(M) emerges... a butterfly-'protecting the natural stuff and delivering the human stuff'. In T. O'Higgins, M. Lago, \& T. H. DeWitt (Eds.), Ecosystem-based management, ecosystem services and aquatic biodiversity: Theory, tools and applications (pp. 61-86). Amsterdam: Springer.

Finisdore, J., Rhodes, C., Haines-Young, R., Maynard, S., Wielgus, J., Dvarkas, A., Houdet, J., Quétier, F., Ding, H., Soulard, F., Van Houtven, G., \& Rowcroft, P. (2018). Expanding the field of ecosystem services practitioners-18 benefits from using classification systems. Sustainable flows working paper. December 2018. 
Foley, M. M., Armsby, M. H., Prahler, E. E., Caldwell, M. E., Erickson, A. L., Kittinger, J. N., Crowder, L. B., \& Levin, P. S. (2013). Improving ocean management through the use of ecological principles and integrated ecosystem assessments. BioScience, 63(8), 619-631.

Fulford, R. S., Heymans, S. J. J., \& Wu, W. (2020). Mathematical modelling for ecosystem-based management (EBM) and ecosystem goods and services (EGS) assessment. In T. O'Higgins, M. Lago, \& T. H. DeWitt (Eds.), Ecosystem-based management, ecosystem services and aquatic biodiversity: Theory, tools and applications (pp. 275-290). Amsterdam: Springer.

Gibble, R., Miller, L., \& Harwell, M. C. (2020). Using stakeholder engagement, translational science and decision support tools for ecosystem-based management in the Florida Everglades. In T. O’Higgins, M. Lago, \& T. H. DeWitt (Eds.), Ecosystem-based management, ecosystem services and aquatic biodiversity: Theory, tools and applications (pp. 517-542). Amsterdam: Springer.

Gregory, R., Failing, L., Harstone, M., Long, G., McDaniels, T., \& Ohlson, D. (2012). Structured decision-making: A-practical guide to environmental management choices. West Sussex, UK: Wiley-Blackwell.

Grumbine, R. E. (1994). What is ecosystem management? Conservation Biology, 8, 27-38.

Haines-Young, R., \& Potschin, M. (2018). Common international classification of ecosystem services (CICES) V5.1 guidance on the application of the revised structure. Fabis Consulting, UK. Retrieved October 28, 2019, from https://cices.eu/content/uploads/sites/8/2018/01/Guid ance-V51-01012018.pdf.

Harwell, M. C., \& Molleda, J. L. (2018). FY 16 output SHC 2.61.1 ecosystem goods and services production and benefits case studies report. EPA/600/R-18/189. Gulf Breeze, FL: U.S. Environmental Protection Agency.

Harwell, M.C., Molleda, J. L., Jackson, C. A., \& Sharpe, L. (2020). Establishing a common framework for strategic communications in the natural sciences. In T. O'Higgins, M. Lago, \& T. DeWitt (Eds.), Ecosystem-based management, ecosystem services and aquatic biodiversity: Theory, tools, and applications (pp. 165-188). Amsterdam: Springer.

Johnston, J. M., Zomer, R., \& Mingcheng, W. (2020). Predicting future vegetated landscapes under climate change: Application of the environmental stratification methodology to protected areas in the Lower Mekong Basin. In T. O'Higgins, M. Lago, \& T. DeWitt (Eds.), Ecosystem-based management, ecosystem services and aquatic biodiversity: Theory, tools, and applications (pp. 561-580). Amsterdam: Springer.

Landers, D., \& Nahlik, A. (2013). Final ecosystem goods and services classification system (FEGSCS). EPA/600/R-13/ORD-004914. Washington, DC: U.S. Environmental Protection Agency.

Landers, D., Nahlik, A., \& Rhodes, C. R. (2016). The beneficiary perspective-benefits and beyond. In M. Potchin, R. Haines-Young RFish, \& K. Turner (Eds.), Routledge handbook of ecosystem services (pp. 74-87). New York, NY: Routledge.

Lewis, N. S., Marois, D. E., Littles, C. J., \& Fulford, R. S. (2020). Projecting changes to coastal and estuarine ecosystem goods and services-Models and tools. In T. O'Higgins, M. Lago, \& T. DeWitt (Eds.), Ecosystem-based management, ecosystem services and aquatic biodiversity: Theory, tools, and applications (pp. 235-254). Amsterdam: Springer.

Marcot, B. G., Thompson, M. P., Runge, M. C., Thompson, F. R., McNulty, S., Cleaves, D., Tomosy, M., Fisher, L. A., \& Bliss, A. (2012). Recent advance in applying decision science to managing national forests. Forest Ecology and Management, 285, 123-132.

Maseyk, F. J. F., Mackay, A. D., Possingham, H. P., Dominati, E. J., \& Buckley, Y. M. (2017). Managing natural capital stocks for the provision of ecosystem services. Conservation Letters, $10,211-220$.

McKane, R. B., Brookes, A., Djang, K., Halama, J., Barnhart, B., Russell, M., Vache, K., \& Bolte, J. (2020). A community-based decision support tool for flexible, interactive assessments that quantify tradeoffs in ecosystem goods and services for alternative decision scenarios. In T. O'Higgins, M. Lago, \& T. DeWitt (Eds.), Ecosystem-based management, ecosystem services and aquatic biodiversity: Theory, tools, and applications (pp. 255-274). Amsterdam: Springer. 
MEA (Millennium Ecosystem Assessment). (2005). Ecosystems and human well-being: Synthesis. Washington, DC: Island Press.

Munns, W. R., Jr., Poulsen, V., Gala, W. R., Marshall, S. J., Rea, A. W., Sorensen, M. T., \& von Stackelberg, K. (2017). Ecosystem services in risk assessment and management. Integrated Environmental Assessment and Management, 13, 62-73.

Myer, M., \& Johnston, J. M. (2020). Models and mapping tools to inform resilience planning after disasters: A case study of hurricane Sandy and Long Island (NY) ecosystem services. In T. O’Higgins, M. Lago, \& T. DeWitt (Eds.), Ecosystem-based management, ecosystem services and aquatic biodiversity: Theory, tools, and applications (pp. 417-430). Amsterdam: Springer.

Nahlik, A. M., Kentula, M. E., Fennessy, M. S., \& Landers, D. H. (2012). Where is the consensus? A proposed foundation for moving ecosystem service concepts into practice. Ecological Economics, 77, 27-35.

Ojea, E., Martin-Ortega, J., \& Chiabai, A. (2012). Defining and classifying ecosystem services for economic valuation: The case of forest water services. Environment: Science and Policy, 19, $1-15$.

Piet, G., Delacámara, G., Gómez, C. M., Lago, M., Martin, R., \& van Duinen, R. (2017). Making ecosystem-based management operational: Deliverable 8.1 executive summary. Report as part of the Horizon 2020 project AQUACROSS (Knowledge, Assessment, and Management for AQUAtic Biodiversity and Ecosystem Services aCROSS EU policies). Retrieved October 28, 2019, from https://aquacross.eu/sites/default/files/AQUACROSS\%20Executive\%20Sum mary\%20D8.1_v2_18062018.pdf.

Piet, G., Delacamara, G., Kraan, M., Röckmann, G. C., \& Lago, M. (2020). Advancing aquatic ecosystem-based management with full consideration of the social-ecological system. In T. O'Higgins, M. Lago, \& T. H. DeWitt (Eds.), Ecosystem-based management, ecosystem services and aquatic biodiversity: Theory, tools and applications (pp. 17-38). Amsterdam: Springer.

Potschin-Young, M., Czucz, B., Liquete, C., Maes, J., Rusch, G. M., \& Haines-Young, R. (2017). Intermediate ecosystem services: An empty concept? Ecosystem Services, 27, 124-126.

Ringold, P., Boyd, J., Landers, D., \& Weber, M. (2013). What data should we collect? A framework for identifying indicators of ecosystem contributions to human well-being. Frontiers in Ecology and the Environment, 11, 98-105.

Robinson, L.A. \& Culhane, F.E. (2020). Linkage frameworks: An exploration tool for complex systems in ecosystem-based management. In T. O'Higgins, M. Lago, \& T. DeWitt (Eds.), Ecosystem-based management, ecosystem services and aquatic biodiversity: Theory, tools, and applications (pp. 213-234). Amsterdam: Springer.

Russell, M. J., Rhodes, C., Sinha, R. K., Van Houtven, G., Warnell, G., \& Harwell, M. C. (2020). Ecosystem-based management and natural capital accounting. In T. O'Higgins, M. Lago, \& T. H. DeWitt (Eds.), Ecosystem-based management, ecosystem services and aquatic biodiversity: Theory, tools and applications (pp. 149-164). Amsterdam: Springer.

Schlueter, M., McAllister, R. R. J., Arlinghaus, R., Bunnefeld, N., Eisenack, K., Hoelker, F., Milner-Gulland, E. J., Müller, B., Nicholson, E., Quaas, M., \& Stöven, M. (2012). New horizons for managing the environment: A review of coupled social-ecological systems modeling. Natural Resource Modeling, 25(1), 219-272.

Sharpe, L., Hernandez, C., \& Jackson, C. (2020). Prioritizing stakeholders, beneficiaries and environmental attributes: A tool for ecosystem-based management. In T. O'Higgins, M. Lago, \& T. H. DeWitt (Eds.), Ecosystem-based management, ecosystem services and aquatic biodiversity: Theory, tools and applications (pp. 189-212). Amsterdam: Springer.

US EPA (United States Environmental Protection Agency). (2015). National ecosystem services classification system (NESCS): Framework design and policy application. EPA-800-R-15-002. Washington, DC: United States Environmental Protection Agency. 
Villa, F., Bagstad, K. J., Voigt, B., Johnson, G. W., Portela, R., Honzak, M., \& Batker, D. (2014). A methodology for adaptable and robust ecosystem services assessment. PLoS ONE, 9(3), e91001.

Wainger, L., \& Mazzotta, M. (2011). Realizing the potential of ecosystem services: A framework for relating ecological changes to economic benefits. Environmental Management, 48, 710-733.

Williams, K. C., \& Hoffman, J. C. (2020). Remediation to restoration to revitalisation: Ecosystembased management to support community engagement at clean-up sites in the Laurentian Great Lakes. In T. O’Higgins, M. Lago, \& T. H. DeWitt (Eds.), Ecosystem-based management, ecosystem services and aquatic biodiversity: Theory, tools and applications (pp. 543-560). Amsterdam: Springer.

Yee, S., Bousquin, J., Bruins, R., Canfield, T. J., DeWitt, T. H., de Jesús-Crespo, R., Dyson, B., Fulford, R., Harwell, M. C., Hoffman, J., Littles, C. J., Johnston, J. M., McKane, R. B., Green, L., Russell, M., Sharpe, L., Seeteram, N., Tashie, A., \& Williams, K. (2017). Practical strategies for integrating final ecosystem goods and services into community decision-making. EPA/600/R-17/266. Gulf Breeze, FL: U.S. Environmental Protection Agency.

Yee, S., Cicchetti, G., DeWitt, T. H., Harwell, M. C., Jackson, S. K., Pryor, M., Rocha, K., Santavy, D. L., Sharpe, L., \& Shumchenia, E. (2020). The ecosystem services gradient: A descriptive model for identifying thresholds of meaningful change. In T. O'Higgins, M. Lago, \& T. DeWitt (Eds.), Ecosystem-based management, ecosystem services and aquatic biodiversity: Theory, tools and applications (pp. 291-308). Amsterdam: Springer.

Open Access This chapter is licensed under the terms of the Creative Commons Attribution 4.0 International License (http://creativecommons.org/licenses/by/4.0/), which permits use, sharing, adaptation, distribution and reproduction in any medium or format, as long as you give appropriate credit to the original author(s) and the source, provide a link to the Creative Commons licence and indicate if changes were made.

The images or other third party material in this chapter are included in the chapter's Creative Commons licence, unless indicated otherwise in a credit line to the material. If material is not included in the chapter's Creative Commons licence and your intended use is not permitted by statutory regulation or exceeds the permitted use, you will need to obtain permission directly from the copyright holder.

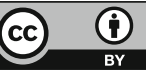

